\title{
A Study of Viral Infections in Renal Transplant Recipients Risk Factors, Clinical Profile And Outcome Analysis
}

\author{
Dr.R.Arul ${ }^{1}$, Dr.P.Praveen Kumar ${ }^{2}$ \\ ${ }^{1}$ Assistant Professor In Nephrology, Coimbatore Medical College Hospital, Coimbatore. \\ ${ }^{2}$ Junior Resident In General Medicine, Coimbatore Medical College Hospital, Coimbatore.
}

\begin{abstract}
Introduction: Renal transplantation has become the most effective means of rehabilitating patients with end stage renal disease. In well-established centers, $90 \% 1$ year graft survival and $95 \%$ patient survival is achieved. In spite of this, infection occurs more than $60 \%$ of renal transplant recipients and being the one of the main cause of death in renal transplant recipients. If the net state of immunosuppression is minimal then an overwhelming exposure only causes the disease. . Routine antimicrobiologic prophylaxis is aimed at common infection i.e. That includes trimethoprim-sulphamethoxazole (toxoplasmosis, pneumocystis, Nocardia, UTI) and valganciclovir( CMV and herpes groups) and antifungal (Kidney-pancreas transplantation). In this study, attempt has been made to analyze the risk factors, clinical profile and outcome of viral infection in renal transplant recipient.
\end{abstract}

Methods: It is a cross-sectional, descriptive, prospective and retrospective study of 356 patients conducted in the department of Nephrology. Renal transplant recipients diagnosed with viral infections were included in the study.

Results: Bacterial, viral, fungal and parasitic infection contributes to 45\%,30.5\%,9.5\%,5.3\% respectively to the total infective episodes. Most of the viral episodes occurred after 6 months post-transplant. Commonest viral infection is the CMV and its prevalence 17.4\% and mean time of onset is between 1-6 months after transplantation. On Univariate analysis, antirejection therapy and NODAT had statistical significant risk factor for developing viral infection $(P<0.05)$. In patients affected with viral infection on univariate analysis, there is a statistical significance for graft dysfunction, graft loss and death $(P<0.05)$. CMV infection has a statistical significant risk factor for bacterial, fungal and other viral infections. $(P<0.05)$. Hepatitis $C$ infection is the second most common virus found in our study. The mean onset of infection is seen 6 months after transplant. Nearly 50\% HCV infected patients developed NODAT.

Conclusion: The clinical profile of the patients in post renal transplant cases is studied. In this study, attempt has been made to analyze the risk factors and outcome of viral infection in renal transplant recipient.

\section{Introduction}

Renal transplantation has become the most effective means of rehabilitating patients with end stage renal disease. In well-established centers, 90\% 1 year graft survival and 95\% patient survival is achieved. In spite of this, infection occurs more than $60 \%$ of renal transplant recipients and being the one of the main cause of death in renal transplant recipients. The factors give a challenge to the clinician for preventing the infection are: (a)Combination of life long immunosuppressive therapy (b)Potential source of infection -endogenous, environmental and allograft itself. Risk of infections in transplant recipients ${ }^{2}$ (a)The occurrence of technical / anatomical mishaps that result in devitalized tissue, fluid collections, prolonged keeping of drains, catheter, endotracheal tubes, vascular access devices which compromise the barrier.(b) The epidemiological exposure of the patient encounters divided into those occur in the community and another is those occurring in the hospital and donor derived and recipient derived exposures. (c)individuals net state of immunosuppression.

The interaction between the net state of immunosuppression and the environmental exposure should be a semi quantitative one. If the net state of immunosuppression is minimal then an overwhelming exposure only causes the disease. . Routine antimicrobiologic prophylaxis is aimed at common infection i.e. That includes trimethoprim-sulphamethoxazole (toxoplasmosis , pneumocystis, Nocardia, UTI) and valganciclovir( CMV and herpes groups) and antifungal (Kidney-pancreas transplantation). In this study, attempt has been made to analyze the risk factors, clinical profile and outcome of viral infection in renal transplant recipient.

\section{Methodology}

It is a cross-sectional, descriptive, prospective and retrospective study of 356 patients conducted in the department of Nephrology in Coimbatore medical college hospital over a period of two years. Ethical committee clearance was obtained from the hospital. 


\section{Inclusion criteria:}

Renal transplant recipients diagnosed with viral infections diagnosed by either clinical, laboratory evidence, serological methods, radiological or by renal biopsy.

\section{Exclusion criteria:}

Renal transplant recipients with empirical antiviral therapy given. This study was done in prospective and retrospective manner. Retrospective cases were selected by examining the case records and examining the patients while coming for follow up and in prospective cases are followed during the time. Baseline characteristics of all patients were presented descriptively with mean \pm SD for continuous variables and percentage for categorical variables. We used Mann-Whitney test for univariate comparison of continuous variables and Fisher exact $t$ test for categorical variables. Multivariate analysis was done by binary logistic regression analysis. $\mathrm{p}$ value of less than 0.05 was considered as statistically significant. It was performed using medcalc software.

\section{Results And Observation}

There were 356 patients analyzed in a prospective and retrospective manner. Mean age of recipient was 29.8 years. Mean age of donor was 41.7 years. Male: female ratio=3.7:1. Live: cadaver=4.08:1.

Immunosuppressive regimens commonly used were

1.) $\mathrm{CSA} / \mathrm{AZA} / \mathrm{PDN}-233(65.4 \%)$

2.) $\mathrm{CYCLO} / \mathrm{MMF} / \mathrm{PDN}-46(12.9 \%)$

3.) $\mathrm{TACRO} / \mathrm{MMF} / \mathrm{PDN}-75$ (21.0\%)

4.) TACRO/AZA/PDN-2(0.5\%)

Induction therapy was given in 8 patients.ATG-3 patients and IL2 receptor antagonists-5 patients. Total infective episodes were 741.

\section{Viral infection:}

Total no. of viral infective episodes was 224 . Total no. of persons affected by viral infection-152 (42.6\%).On an average 72 persons have more than one viral infective episode. Male: female -3.47:1. Live : cadaver: 5.04:1.

Diagram-1 Total infective episodes

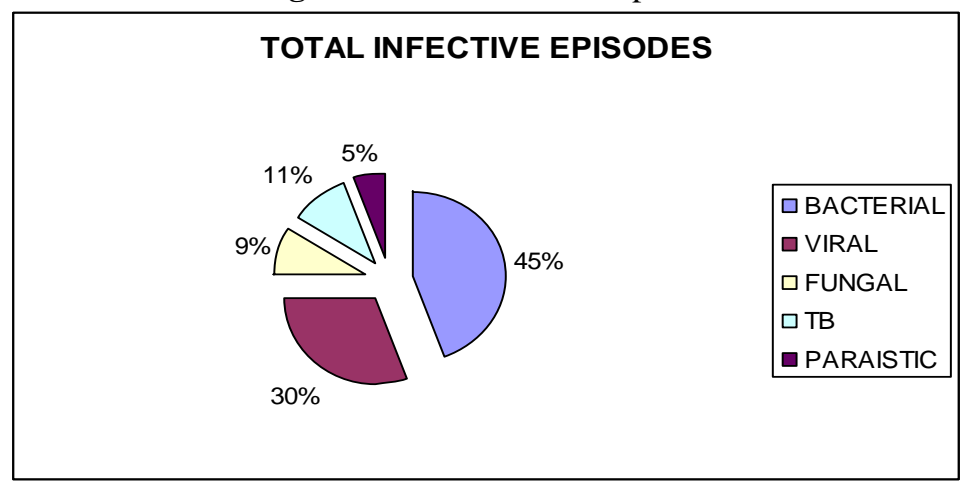

Diagrram-2 Percentage of viral infection

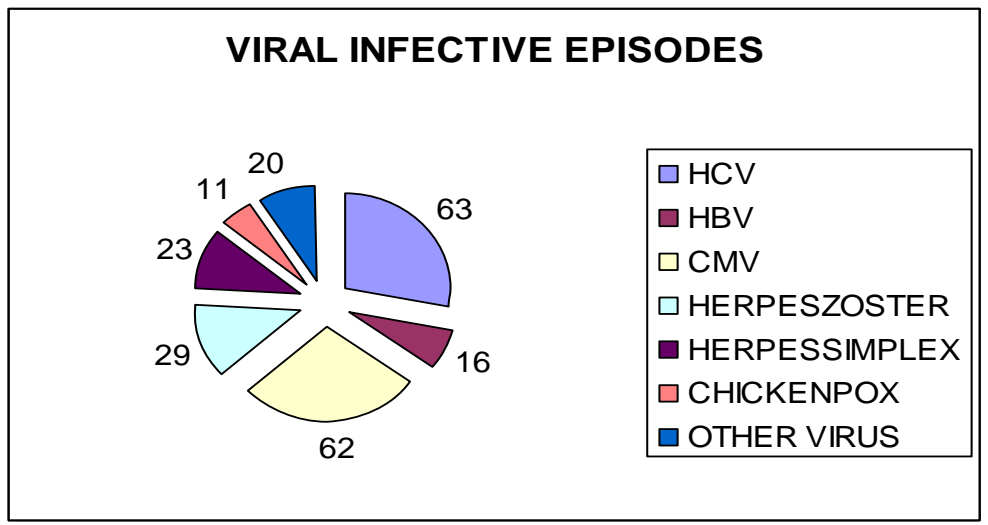

Diagram-3 Other virus infection 


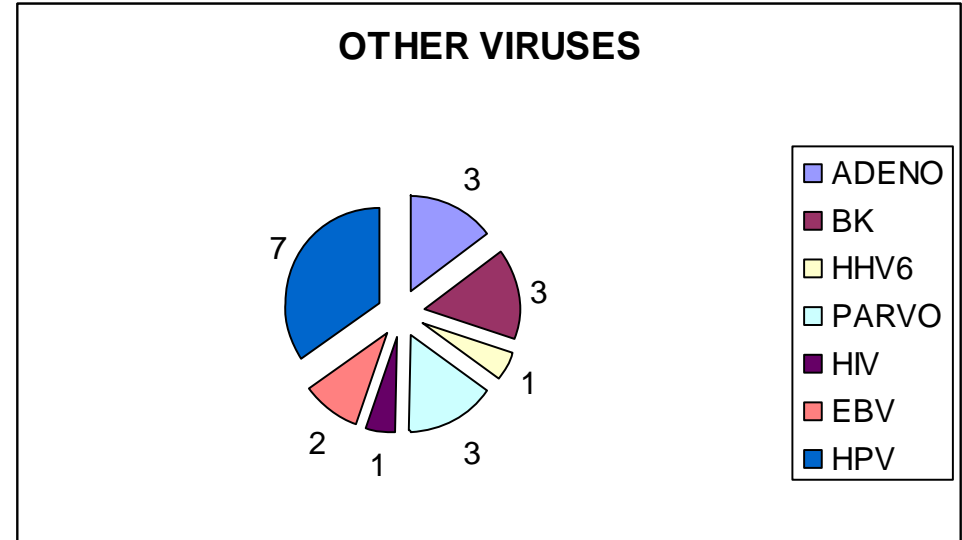

Onset of viral infections:

Phase I( <1 month) -9episodes $(4 \%)$

Phase II(1-6 month)-74episodes(33\%)

Phase III(>6 month)---119 episodes((53.1\%).

Risk factors:

NODAT ( New onset diabetes after transplant):53persons(34.8\%)

ART: 55 persons $(36.1 \%)$

Cni toxicity: 44 persons $(28.9 \%)$

Table-1 Relation between Risk factors and viral infection

\begin{tabular}{|l|l|l|l|}
\hline & With viral infection & Without viral infection & $\begin{array}{l}\text { P } \\
\text { value }\end{array}$ \\
\hline NODAT & 53 & 27 & $<0.001$ \\
\hline Anti-rejection therapy & 55 & 45 & $<0.004$ \\
\hline CNI toxicity & 44 & 76 & 0.113 \\
\hline
\end{tabular}

Nodat and ART is the significant risk factor for the development of viral infection.

\section{Outcome :}

Graft dysfunction-51(33.5\%)

Graft loss-15(9\%)

Death-18(11.8\%)

Table-2 Transplant rejection and viral infection

\begin{tabular}{|l|l|l|l|}
\hline & GDF & Graft loss & Death \\
\hline With viral infection & 51 & 15 & 18 \\
\hline Without viral infection & 71 & 55 & 78 \\
\hline P value & $<0.001$ & $<0.001$ & $<0.001$ \\
\hline
\end{tabular}

Viral infection is one of the most contributing factor for the persistent graft dysfunction and graft loss and death of the patient.

\section{Cytomegalovirus infection:}

Total persons affected by CMV were 62. Prevalence of CMV infection was $17.4 \%$. Mean time of onset was $4+1$ month after transplantation.Leucopenia is present in $72.5 \%$ of patients. It is the one of the associative factor in active CMV infection $(\mathrm{P}<0.001)$.

\section{Risk factors:}

Table-3 Cmv Infection And Transplant Rejection

\begin{tabular}{|l|l|l|l|}
\hline & With CMV & Without CMV & P value \\
\hline NODAT & 15 & 65 & 0.7387 \\
\hline Anti-rejection therapy & 27 & 83 & $<0.03$ \\
\hline CNI toxicity & 24 & 100 & 0.556 \\
\hline
\end{tabular}

Anti-rejection therapy is the most contributing factor for development of CMV infection. 
Table-4 Associated other infection:

\begin{tabular}{|l|l|l|l|l|}
\hline & Fungal infection & TB & Bacterial infn & Other viral infn \\
\hline CMV +ve & 19 & 6 & 18 & 22 \\
\hline CMV-ve & 26 & 29 & 162 & 130 \\
\hline P value & $<0.01$ & 1.07 & $<0.002$ & $<0.002$ \\
\hline
\end{tabular}

CMV infection is a risk factor for developing bacterial and other viral infection and fungal infection $(\mathrm{p}<0.05)$ but not for tuberculosis. (P-1.07 - not statistically significant).

\section{Bk virus infection:}

Total no. of patients affected were 3.The mean time of onset after transplantation was 8 month+4month.

\section{Hepatitis virus:}

Total no of patients affected by HCV were 63. Pre transplant Hepatitis C positive was 20. Mean onset of HCV infection-14+2.6 months.

Table-5 Hcv Vs Outcome

\begin{tabular}{|l|l|l|l|}
\hline & NODAT & GDF & Death \\
\hline Hep C +ve & 35 & 19 & 5 \\
\hline Hep C -ve & 45 & 113 & 91 \\
\hline P value & $<0.009$ & 0.2506 & $<0.001$ \\
\hline
\end{tabular}

$55.5 \%$ of patients developing NODAT in $\mathrm{HCV}+$ ve patients. ( pvalue $<0.009$ )

Hepatitis B infection was seen in 16.

\section{Herpes zoster infection:}

Total no. of patients affected was 29. Mean time of onset was 9 months after transplant. Prevalence was $8.1 \%$.

\section{Herpes simplex infection:}

Total number of patients affected was 23. Mean Time of onset was 7 month +3 months after transplantation. Prevalence was $6 \%$.

\section{Ebstein barr virus:}

Total number of patients was 2. Both patient had graft dysfunction. One patient had a history of ART and treated CMV with renal biopsy shows plenty of interstitial lymphocyte infiltration. One patient presented as pulmonary nodule and hilar lymphadenopathy.

\section{Parvo virus:}

Total number of patients was 3. Two patients presented as pure red cell aplasia. One patients had collapsing glomerulopathy.

\section{Human papilloma virus:}

Total number of patients was 7. Prevalence was $1.9 \%$. Mean time at the onset was 18 month+6month.

\section{Discussion}

In our study 356 patients were taken, of which 152 persons (42.6\%) were affected by viral infection. Total Number of viral infective episodes was 224.Total infective episodes were 741. Bacterial infection excluding mycobacterium TB accounts for $45 \%$. Viral infections accounts for $30.5 \%$. Fungal infection accounts for $9.5 \%$ and mycobacterium TB accounts for $10.8 \%$ and parasitic infection accounts for 5.2\%. Dharnidharka et al found that bacterial infection is twice as frequent as viral infections and among bacterial infections. Vascular access and urinary tract infections are the commonest and among viral infection cytomegalovirus infection are the commonest. We divided into 3 phases. First phase was less than one month after transplantation. Second phase 1-6 months and third phase more than 6 months. Out of 3 phases Phase III has more viral infective episodes $(53.1 \%)$ and followed by Phase II (33\%) and lastly Phase I (4\%).In Phase II CMV infection is the commonest. Stratta et al in $1^{\text {st }}$ month bacterial infection is the commonest and $2^{\text {nd }}-4^{\text {th }}$ month CMV predominates the bacterial and mean timing of bacterial infection is 60 days and mean onset of CMV is 70 days and non CMV viral is 145 days and fungal is 163 days. Most of the risk factors analyzed for developing viral infection are state of immunosuppressant and antirejection therapy and NODAT and CNI toxicity and graft 
dysfunction. In our study anti-rejection therapy (p-0.004) and NODAT(P-0.001) are the significant risk factors for developing viral infection. In the outcome analysis , 53.5\% of viral infected persons have persistent graft dysfunction. The Graft loss occur in $9 \%$ of persons in our viral infected study population and death occurred in $11.8 \%$ of patients . Viral infection is the one of the majordetermining factor for graft and patient survival.

Bacterial, viral, fungal and parasitic infection contributes to $45 \%, 30.5 \%, 9.5 \%, 5.3 \%$ respectively to the total infective episodes.Most of the viral episodes occurred after 6 months post-transplant.Commonest viral infection is the CMV and its prevalence 17.4\% and mean time of onset is between 1-6 months after transplantation.On Univariate analysis, antirejection therapy and NODAT had statistical significant risk factor for developing viralinfection $(\mathrm{P}<0.05)$. In patients affected with viral infection on univariate analysis, there is a statistical significance for graft dysfunction, graft loss and death $(\mathrm{P}<0.05)$. CMV infection has a statistical significant risk factor for bacterial, fungal and other viral infections. $(\mathrm{P}<0.05)$. Hepatitis $\mathrm{C}$ infection is the second most common virus found in our study. The mean onset of infection is seen 6 months after transplant. Nearly $50 \%$ HCV infected patients developed NODAT. Lamivudine resistance is more common in posttransplant situation because prolonged treatment isnecessary.All the three patients with BK virus infection had persistent and progressive graft dysfunction.Multi dermatomal involvement is commonly seen in our patients with herpes zoster $(56 \%)$.

\section{Conclusion}

Renal transplantation has become the most effective means of rehabilitating patients with end stage renal disease. Thus the clinical profile of the patients in post renal transplant cases is studied. In this study, attempt has been made to analyze the risk factors and outcome of viral infection in renal transplant recipient.

\section{References}

[1]. Nina E. Tolkoff-Rubin and Robert H. Rubin-infection in Renal transplant recipients-Massory\&Glassock Text book of Nephrology.

[2]. Joy A. Fishman MD infection in Renal transplant Recipients : semininNeph vol27, No4, jul 2007 445-461

[3]. Camille N. Kotton and Jay A. Fishman viral infection in the Renal transplant recipient. JASN 16:1758-1774, 2005

[4]. Rubin RH: The direct and indirect effects of infection in liver transplantation:

a. currclinTopInfec Dis 22:125-154,2002

[5]. Mitchell BM, Bloom DC, Cohrs Herpes simplex virus-1 and varicella zoster virus latency in ganglia. J Neurovirol 9:194-204, 2003

[6]. Karras A, Thervet E:hemophagocytic syndrome in renal transplant recipients: Transplant 77;238-243

[7]. Zhang Z, Kim SJ etal TNF receptor independent activation of CMV;Transplantation 2008:85(7)1033-45

[8]. Chapenko S , Folkmane I : Coinfection of two beta herpesviruses as an increased risk factor for CMV disease Clin Transplant 14:486-492, 2000.

[9]. Rubin RH , The indirect effects of CMV infection on the outcome of organ transplantation JAMA 1989:261:3607-3609

[10]. Kalli AC, Levitsky J Meta analysis. The efficacy of strategies to prevent organ disease by CMV in solid organ Transplant Ann intern Med 2005:143:87-90

[11]. Asberg A, Humar A et al Oral ganciclovir is non inferior to IV ganciclovir for treatment of CMV. Am J Trans 2007:7(9)2106-13

[12]. Kristel De Keyzer, Stenven Human CMV and kidney transplantation Am J Kid dis 2011:58(1)118-126

[13]. Benvoisisn C, Weekers L, Xhignesse P Polyoma virus in Renal Transplantion Transplantation 2008: 85;S42-48

[14]. Dugan AS, Eash S Update on BK virus - entry and intracellular trafficking. Trans inf Dis 2006;8:62

[15]. Randhawa P, Brennan DC Bk virus infection in transplant recipients Am J trans 2006:6:2000-2005 